\title{
Clinical curative effect of repair surgery for treatment of articular cartilage injury.
}

\author{
Guo-Cheng Ding ${ }^{1 \#, ~ H o n g-W e i ~ W a n g ~}{ }^{2 \#}$, Liang-Bi Xiang², Dan-Ni Wang², Xin-Wei Liu2* \\ ${ }^{1}$ Department of Orthopedics, the Graduate School of Dalian Medical University, Dalian, Liaoning, PR China \\ ${ }^{2}$ Department of Orthopedics, Rescue Center of Severe Wound and Trauma of PLA, General Hospital of Shenyang \\ Military Area Command, Shenyang, Liaoning, PR China
}

${ }^{\#}$ These authors contributed equally to this work

\begin{abstract}
Objective: This study aims to determine the clinical efficacy of articular cartilage injury repair surgery. Methods: A total of 112 patients with knee articular cartilage injury who received treatment at our hospital from August 2015 to May 2017 were selected as research subjects. The patients were divided into control and experimental groups (56 patients in each group) through random even-odd number method and treated with arthroscopic joint debridement and arthroscopic microfracture repair surgery, respectively. Clinical treatment effect, HSS score, complication, and surgical result satisfaction were observed and compared between the two groups.

Results: Patients in the experimental group exhibited significantly higher total effective rate than those in the control group $(\mathbf{P}<\mathbf{0 . 0 5})$. The HSS score in the experimental group was higher than that in the control group, and more patients in the former group showed HSS score higher than 85 or between 60-85 and less patients had HSS score less than $60(P<0.05)$. Patients in the control group experienced less satisfaction on the result of surgery and higher complication incidence rate than those in the experimental group; the difference was statistically significant between the two groups $(\mathbf{P}<0.05)$.

Conclusion: Arthroscopic microfracture surgery exerts satisfactory treatment effect for knee articular cartilage injury and can significantly improve patient satisfaction regarding surgery result, improve the articular function and physical action ability of patients, and reduce the incidence rate of complications. Hence, this technique is a feasible option and must be promoted for clinical application.
\end{abstract}

Keywords: Articular cartilage injury, Arthroscopic microfracture repair surgery, Arthroscopic joint debridement. Accepted on November 15, 2017

\section{Introduction}

Articular cartilage injury, one of the most common clinical joint diseases, is mainly caused by internal or external factors, and the incidence rate of knee joint injury is high [1]. The articular cartilage of knee joint lacks blood vessels, nerves, and lymph tissues; thus, the joint exhibits poor self-repair ability. Once joint injury occurs, self-healing is difficult to achieve [2] Improving the treatment effect of articular cartilage injury has become the top priority in the orthopedics field. In recent years, the development and application of arthroscope-assisted surgery have provided a new option for clinical treatment of knee articular cartilage injury [3,4]. In this research, 112 patients with knee articular cartilage injury who received treatment at our hospital from August 2015 to May 2017 were selected as research subjects. The effects of treatment were analysed and reported in this paper.

\section{Data and Methods}

\section{General information}

A total of 112 patients with knee articular cartilage injury who received treatment at our hospital from August 2015 to May 2017 were selected as research subjects. All patients were diagnosed by MRI examination before operation, and the contraindication of operation was excluded. These patients were equally divided into control and experimental groups according to the random even odd number method. The control group comprised 36 males and 20 females aged 19-56 y, with an average age of $34.8 \pm 6.1$. The experimental group consisted of 37 males and 19 females aged 20-57 y, with an average age of $35.2 \pm 6.2$. The basic data of patients in the two groups were entered into the corresponding version of statistical software for analysis. The results indicate that no significant difference between the two groups $(\mathrm{P}>0.05)$; thus, a comparison can be performed. 


\section{Methodology}

Patients in control group were treated by arthroscopic joint debridement, and the surgery incision was performed at the knee joint under arthroscope-assisted surgery. A cutter, planer tool, bending curette, and probe were used for the treatment of cartilage injury. Loose cartilage was removed, and the articular cavity was rinsed. After the operation, cold compress was adopted to treat the knees. Based on the specific site, severity, and recovery effect of the cartilage, a scientific and appropriate rehabilitation training program was developed for each patient within 2-3 d after the surgery. Patients in the experimental group were treated by arthroscopic microfracture repair surgery, whereby the patients were required to lie on a bed in supine position and treated with epidural anesthesia according to the conventional method. Three standard arthroscope entrances were made on the knee in order to install the water pipe, surgical instrument, and arthroscope. The arthroscope was used to inspect and treat the knee joint of patients. All non-healthy cartilages in the injured cartilage were cleaned up, and the calcified cartilage layer at the bottom of the lesion was removed. After completely cleaning up the joint injury, a microfracture pointed cone was used for vertical drilling in the injured articular cartilage until its center was reached. The microfracture holes should be distributed around the center of injury, and the hole spacing should be as small as possible. Under normal circumstances, the best criterion was 3-4 holes $/ \mathrm{cm}^{2}$. After drilling, some bone marrow and blood exuded from the bone marrow cavity and were presented in the form of blood clots. Abundant stem cells in the blood clot could promote the formation of new articular cartilage. The excess exudates in the joint were removed, and the operation was completed after the arthroscope withdrawal. The rehabilitation training was performed after the surgery according to the control group method.

\section{Observation index}

HSS scoring method is used to evaluate the muscle strength, pain, activity function, and recovery status of the knee joints of patients. A higher score indicates better recovery of knee articular function. Tegner method was adapted to rate the exercise capacity of patients. Three-month follow-up visits were implemented after the surgery in order to evaluate complications, such as delayed wound healing, deep venous thrombosis, and wound infection. The nursing satisfaction questionnaire of the hospital was used to evaluate the satisfaction of patients on the result of surgery. A 100-point system was adopted, and scores $>85,60-85$, and $<60$ indicated extremely satisfactory, satisfactory, and unsatisfactory responses, respectively.

\section{Efficacy evaluation criteria}

The surgery was considered markedly effective if after performing the surgery, symptoms of knee joint injury disappeared, or knee joint recovered to the status before injury, the ability of the knee joint to move and work reverted to normal, HSS score was $>85$, and was rated as level 4 according to the Tegner rating method. The surgery was considered effective if symptoms of knee joint injury disappeared or the knee joint has not yet recovered to the state before injury, the ability of the knee joint to move and work improved significantly, HSS score was 60-85, and rated as levels 3 and 4 according to the Tegner rating method. The surgery was considered ineffective if no significant changes in symptoms of knee joint injury and articular function were observed, the symptoms worsened from those before treatment, HSS score was less than 60 , and rated as level 2 or below. The sum of markedly effective and effective percentages was the total effective rate of treatment.

\section{Statistical processing method}

SPSS 22.0 statistical software package was used to analyse and process relevant data, HSS scoring was described as $(\overline{\mathrm{x}} \pm \mathrm{s})$ and was compared with t-test. The total effective rate of treatment, nursing satisfaction, and incidence rates of complication were described as percentages $(\%) . \chi^{2}$ test was used for comparison between two groups A P value of $<0.05$ indicated statistically significant differences between the two groups.

\section{Results}

\section{Comparison of treatment effect between the two groups}

The total effective rates of treatment in the experimental and control groups were $96.4 \%$ and $80.4 \%$ respectively. The statistical comparison results indicated that the treatment effect in the control group was significantly lower than that in the experimental group $(\mathrm{P}<0.05)$ (Table 1$)$.

Table 1. Comparison of treatment effect between two groups ( $n(\%))$.

\begin{tabular}{lllll}
\hline Group & $\begin{array}{l}\text { Markedly } \\
\text { effective }\end{array}$ & Effective & Ineffective & $\begin{array}{l}\text { Total } \\
\text { effective rate }\end{array}$ \\
\hline $\begin{array}{l}\text { Control Group } \\
(\mathrm{n}=56)\end{array}$ & $25(44.6)$ & $20(35.7)$ & $11(19.6)$ & $45(80.4)$ \\
\hline $\begin{array}{l}\text { Experimental } \\
\text { Group }(\mathrm{n}=56)\end{array}$ & $32(57.1)$ & $22(39.3)$ & $2(3.6)$ & $54(96.4)$ \\
\hline $\mathrm{X}^{2}$ & & & 7.0490 \\
\hline $\mathrm{P}$ & & & 0.0079 \\
\hline
\end{tabular}

\section{Comparison of HSS scores between two groups}

The HSS scores in the experimental and control groups were $84.22 \pm 7.24$ and $62.96 \pm 6.13$, respectively. The HSS score in the experimental group was higher than that in the control group ( $\mathrm{t}=16.7706, \mathrm{P}=0.0000)$. Significant differences between the two groups were observed after comparing the HSS scores that were $>85,60-85$, or $<60$ in the experimental and control groups $(\mathrm{P}<0.05)$ (Table 2$)$.

Table 2. Comparison of HSS scores between the two groups ( $n(\%))$. 


\begin{tabular}{|c|c|c|c|}
\hline Group & Score $>85$ & $\begin{array}{l}\text { Score } \\
60-85\end{array}$ & Score $<60$ \\
\hline $\begin{array}{l}\text { Control } \\
(n=56)\end{array}$ & $14(25.0)$ & $17(30.4)$ & $25(44.6)$ \\
\hline $\begin{array}{l}\text { Experimental } \\
\text { Group }(n=56)\end{array}$ & $24(42.9)$ & $28(50.0)$ & $3(5.4)$ \\
\hline$x^{2}$ & 4.7601 & 4.4949 & 23.0476 \\
\hline $\mathrm{P}$ & 0.0291 & 0.0339 & 0.0000 \\
\hline
\end{tabular}

\section{Comparison of satisfaction on surgical results between the two groups}

The satisfaction on surgical results of patients in experimental and control groups were $98.2 \%$ and $83.9 \%$, respectively. The satisfaction of patients in the control group was significantly lower than that of patients in the experimental group $(\mathrm{P}<0.05)$ (Table 3).

Table 3. Comparison of satisfaction on surgical results between the two groups $(n(\%))$.

\begin{tabular}{lllll}
\hline Group & $\begin{array}{l}\text { Extremely } \\
\text { satisfactory }\end{array}$ & Satisfactory & $\begin{array}{l}\text { Unsatisfactor } \\
\mathbf{y}\end{array}$ & Satisfaction \\
\hline $\begin{array}{l}\text { Control Group } \\
(\mathrm{n}=56)\end{array}$ & $25(44.7)$ & $22(39.3)$ & $8(14.3)$ & $47(83.9)$ \\
\hline $\begin{array}{l}\text { Experimental } \\
\text { Group }(\mathrm{n}=56)\end{array}$ & $31(55.4)$ & $24(42.9)$ & $1(1.8)$ & $55(98.2)$ \\
\hline $\mathrm{X}^{2}$ & & & 5.9202 \\
\hline$P$ & & & 0.0149 \\
\hline
\end{tabular}

\section{Comparison of complications between the two groups}

The incidence rates of complications in control and experimental groups were $16.1 \%$ and $3.6 \%$, respectively. The incidence rate of complications in the experimental group was significantly lower than that in the control group $(\mathrm{P}<0.05)$ (Table 4).

Table 4. Comparison of complications between the two groups ( $n$ (\%)).

\begin{tabular}{|c|c|c|c|c|c|}
\hline Group & $\begin{array}{l}\text { Wound } \\
\text { infection }\end{array}$ & $\begin{array}{l}\text { Delayed } \\
\text { healing } \\
\text { wound }\end{array}$ & of & $\begin{array}{l}\text { Deep venous } \\
\text { thrombosis }\end{array}$ & Complication \\
\hline $\begin{array}{l}\text { Control } \\
(n=56)\end{array}$ & $5(8.9)$ & $3(5.4)$ & & $1(1.8)$ & $9(16.1)$ \\
\hline $\begin{array}{l}\text { Experimental } \\
(n=56)\end{array}$ & $1(1.8)$ & $1(1.8)$ & & $0(0.0)$ & $2(3.6)$ \\
\hline$x^{2}$ & & & & & 4.9397 \\
\hline$P$ & & & & & 0.0262 \\
\hline
\end{tabular}

\section{Discussion}

In terms of the current medical technology level, articular cartilage injury is mainly treated by arthroscopic repair washing, cartilage cleaning and forming, subchondral bone drilling, arthroscopic microfracture surgery, and other surgical treatment methods [5,6]. Although the above-mentioned surgical methods are different from each other, the pain symptoms induced by joint injury can be effectively alleviated after surgical treatment, and the degenerative joint diseases can be delayed, thus prompting the recovery of articular function as soon as possible [7]. Microfracture surgery has been widely used for clinical surgical treatment since early 1980s. Cartilage surface with poor stability is promptly removed before surgery until healthy cartilage tissue is presented. Subsequently, the subchondral bone located at the joint injury is fully revealed, and microfracture cone drilling is performed on the surface of subchondral bone [8]. The drilling depth must ensure the cartilaginous, osteogenic and marrow cells of the subchondral bone can penetrate into the injured area because penetrated blood clots can attach to the edge of surrounding normal articular cartilage, repairing the injury after forming fibrocartilage and accelerating the recovery rate of articular function [9]. Clinical practices confirmed that microfracture surgery has good treatment effect on the tibial plateau weightbearing area and full-thickness cartilage defect of femoral malleolus. Moreover, it has certain advantages in the treatment for full-thickness cartilage defect in the interface between the patella and femoral trochlea [10]. Microfracture surgery exhibits good treatment effect for the above-mentioned diseases; however, the method is unsuitable for patients with part or full-thickness cartilage defect, subchondral defect of articular cartilage, and other symptoms or diseases. In addition, the imaging results showed that microfracture surgery is not suitable for patients with limb varus or valgus angle more than $5^{\circ}$ or for patients with chondropathy or arthritis caused by systemic immune diseases or other diseases [11].

Results of this research indicate that the total effective rate of treatment group was higher than that of control group, and the incidence rate of complications was lower than that of control group $(\mathrm{P}<0.05)$, which was generally consistent with the conclusions of relevant scholars. The HSS score and satisfaction on surgical results of the treatment group were significantly higher than those of control group $(\mathrm{P}<0.05)$. Microfracture surgery is adopted for the treatment of fullthickness defects of knee articular cartilage, yielding satisfactory results. Microfracture surgery can significantly reduce the incidence rate of postoperative complications. Compared with patients who undergo the conventional joint debridement, those who are treated by microfracture repair surgery have significantly higher HSS score.

\section{Conclusion}

In summary, arthroscopic microfracture surgery exhibits good treatment effect for knee articular cartilage injury. It can significantly improve patient satisfaction on the result of surgery, improve articular function and physical action ability, and reduce the incidence rate of complications; thus, it is worthy as a clinical option and should be promoted. 


\section{Acknowledgments}

This work was supported by grants from the Liaoning province natural science foundation of China (20170540959).

\section{References}

1. Julkunen P, Wilson W, Isaksson H, Jurvelin JS, Herzog W, Korhonen RK. A review of the combination of experimental measurements and fibril-reinforced modeling for investigation of articular cartilage and chondrocyte response to loading. Comput Math Methods Med 2013; 2013: 326150.

2. Goyal K, Agarwal R. Pulse based sensor design for wrist pulse signal analysis and health diagnosis. Biomed Res India 2017; 28: 5187-5195.

3. Shepard JB, Jeong JW, Maihle NJ, Brien SO, Dealy CN. Transient anabolic effects accompany epidermal growth factor receptor signal activation in articular cartilage in vivo. Arthritis Res Ther 2013; 15: 60.

4. Doulabi AH, Mequanint K, Mohammadi H. Blends and nanocomposite biomaterials for articular cartilage tissue engineering. Materials (Basel) 2014; 7: 5327-5355.

5. Preethi DMD, Jayanthi VE. SOM clustering approach: investigation on cataract surgery structural changes in iris. Biomed Res India 2017; 28: 5210-5216.

6. Ray A, Singh PNP, Sohaskey ML, Harland RM, Bandyopadhyay A. Precise spatial restriction of BMP signaling is essential for articular cartilage differentiation. Development 2015; 142: 1169-1179.

7. Ge Q, Xing R, Zhu R, Qu B, Peng D, Chen W. Disturbed pharmacokinetics of magnesium isoglycyrrhizinate in
CCL4-induced liver injury. Lat Am J Pharm 2017; 36: 2012-2017.

8. He B, Wu JP, Kirk TB, Carrino JA, Xiang C, Xu J. Highresolution measurements of the multilayer ultra-structure of articular cartilage and their translational potential. Arthritis Res Ther 2014; 16: 205.

9. Yao H, Zhang X, Wei G, Wu W, Duan J, Li Y, Zhang C, Liu $\mathrm{Y}$. Protective effects of thevetiaflavone on $\mathrm{H} 2 \mathrm{O} 2$-induced pc12 cells injury via improving oxidative stress and mitochondrial dysfunction. Lat Am J Pharm 2017; 36: 1821-1826.

10. Luria A, Chu CR. Articular cartilage changes in maturing athletes: new targets for joint rejuvenation. Sports Health 2014; 6: 18-30.

11. Song J, Dong F, Li X, Xu C, Cui Z, Jiang N, Jia J, Yu B. Effect of treadmill exercise timing on repair of fullthickness defects of articular cartilage by bone-derived mesenchymal stem cells: an experimental investigation in rats. PLoS One 2014; 9: 90858.

\section{*Correspondence to}

Xin-Wei Liu

Department of Orthopedics

Rescue Center of Severe Wound and Trauma of PLA

General Hospital of Shenyang Military Area Command

PR China 